CHARLES ANTWI, ADRIAN FLYNN, PAUL CHRICHARD, AMANDA HADDOCK,

CLAIRE JOHNSON, JO HAMMOND AND PETER AITKEN

\title{
Transferring people with mental illness from emergency department to acute mental health wards: survey of contemporary practice
}

\begin{abstract}
AIMS AND METHOD
A substantial minority of patients attending emergency departments do so with a primary mental health problem. A number will require admission to an acute psychiatric unit. There is little guidance about the best practice in terms of risk assessment and escorting of these patients. We conducted a telephone questionnaire survey of acute trusts, to identify current policies for the
\end{abstract}

\author{
transfer of patients with mental \\ illness to acute psychiatric units. \\ RESULTS \\ Eighty-two trusts were contacted. \\ We could not verify the presence of \\ any current policies. There was \\ considerable variation in the \\ assessment and management of risk \\ in these clinical circumstances.

\section{CLINICAL IMPLICATIONS} \\ Current local service structure and \\ transfer distance may influence the
}

\begin{abstract}
way in which risk is assessed. However, there is a need for trusts to ensure that basic standards of risk assessment are maintained for the transfer of these high-risk patients. We recommend that all emergency departments should have such policies and that liaison psychiatry is well placed to aid their development.
\end{abstract}

The Council Report Psychiatric Services to Accident and Emergency Departments (Royal College of Psychiatrists, 2004) states that at least $5 \%$ of patients presenting to emergency departments do so with a primary mental health problem. It recognises the importance of detecting mental disorder and the difficulty of managing people with severe mental illness in this environment.

A proportion of patients with mental disorder seen in the emergency department will require admission to an acute psychiatric in-patient unit. Such patients may be highly agitated, suicidal or potentially violent. A study has suggested that admissions to psychiatric wards increasingly comprise young men, drug-related problems and emergency department referrals, and there are an increasing proportion of out-of-hours admissions (Tintinalli et al, 1994). The transfer to an acute psychiatric unit from a public area such as the emergency department may include other public as well as clinical settings. Before undertaking such a transfer, important factors such as the dignity of the patient and the risk of absconding or harm to self or others need to be given due consideration. The National Health Service Checklist on improving the management of patients with mental ill-health in emergency care settings recognised transport as one of the key areas requiring attention (Department of Health, 2004).

Transfer should be by the safest but least restrictive means of transporting people from the emergency department to the mental health ward. We are not aware of any current guidance that mandates the development of a policy to ensure safe transfer, but recognise increasingly that such policies must be best practice. Within our own service a variety of means have been used to transfer people with mental illness from the emergency department to the acute psychiatric unit: these include the patient walking, ambulance transfer, police vehicle transfer and private transport. Patients may be escorted by approved social workers, relatives, friends, police or mental health nurses and doctors. Transfer can occur following rapid tranquillisation or sedative medication and should only proceed after the patient has been declared 'medically fit' for transfer. However, evidence suggests that such medical assessments are often incomplete and frequently overlook medical illness (Yates et al, 2000).

In order to establish best contemporary practice we undertook a preliminary literature review of Medline, EMBASE and the Cochrane Library. The search terms ACCIDENT AND EMERGENCY, TRANSFER, MENTAL HEALTH; EMERGENCY PSYCHIATRY, TRANSFER, MENTAL HEALTH; TRANSFER MENTAL HEALTH; and TRANSFER PSYCHIATRY were used. The search yielded a limited number of studies, which addressed principally the transfer of forensic patients between secure mental health sites. This is an altogether different clinical scenario and one from which it is difficult to draw clear guidance. We used this apparent gap in the literature as a basis for conducting a telephone survey of current best practice across England. Having identified all the acute trusts with accident and emergency departments in England, we sought to establish their current practice and to review the key objectives of any policies held. We aimed to identify those that held current transfer policies.

\section{Method}

A semi-structured questionnaire was designed to ascertain key areas of current practice in the transfer of patients with mental illness from the emergency department to an acute psychiatric unit. Particular emphasis was placed on procedures relating to informal and detained patients and the risks assessed.

From the national database of acute trusts in England and Wales, 82 emergency departments were contacted. A telephone interview was undertaken with the senior nurse or clinical services manager. The purpose 
original papers of the call was explained and consent sought for the interview to proceed. The questionnaire sought information regarding the distance between the emergency department and the acute psychiatric unit; the most common method of transfer for both informal and detained patients; the likely escorts for transfer; the risks assessed prior to transfer; and the designation of individuals assessing risk. The interviewees were also asked if their department had a formal transfer policy. Finally a case scenario was given and current best practice established for the following situation:

'A 40-year-old male with mania, verbally aggressive and threatening, under section of the Mental Health Act 1983, having received $2 \mathrm{mg}$ lorazepam'.

Acute trusts that held policies on transfer of psychiatric patients were asked to forward a copy. The survey instrument was piloted on 15 trusts. This identified that at times other than early morning, clinical imperatives made response to the telephone interview difficult. Timing of calls was adjusted accordingly. Non-response was defined as failure to participate in a telephone interview after two separate contacts.

\section{Results}

The response rate was $80 \%(n=66)$. Non-response was mainly owing to emergency clinical work. Thirty-nine (59\%) respondents informed us that their trust had a psychiatric unit on the same site; in five trusts this was in the same building. The distance of these units from the emergency department ranged from $30 \mathrm{~m}$ to $800 \mathrm{~m}$. Off-site psychiatric units were $1.5-16 \mathrm{~km}$ distant. The methods of transfer for detained and informal patients are given in Table 1. Twenty-five (38\%) respondents suggested that registered mental nurses were the most common escorts; 22 (33\%) suggested that paramedic staff would be used. Of the remainder, $21 \%$ of respondents stated the escort would be a registered general nurse, $5 \%$ a doctor and $3 \%$ friends or relatives of the patient.

The risks assessed are listed in Table 2. A range of professionals assessed risk prior to transfer. Where two or more professionals were involved this assessment was categorised as multiprofessional. Forty-one (62\%) respondents reported multiprofessional assessment; in 16 trusts (24\%) a doctor (either an emergency department doctor or a senior house officer from the psychiatric department) undertook the assessment, whereas in other trusts nurses assessed risk prior to transfer. For 8 trusts $(12 \%)$ this was a registered mental nurse and for 1 (2\%) it was a registered general nurse.

In response to the case scenario, 39 (59\%) of the survey participants indicated the need for an ambulance for transfer and would involve the police. Five (7.5\%) indicated ambulance transfer and hospital security and 7 (11\%) would include staff (psychiatric senior house officer, or registered mental or general nurse) plus hospital security to ensure safe transfer. Ambulance only was suggested in $5(8 \%)$ cases. The remaining $14 \%$ suggested other means, including hospital car and police vehicle escort, walk with the police or hospital trolley.
Table 1. Method of patient transfer

\begin{tabular}{|c|c|c|}
\hline \multirow[b]{2}{*}{ Method of transfer } & \multicolumn{2}{|c|}{ Trust responses, $n(\%)$} \\
\hline & Detained patients & Informal patients ${ }^{1}$ \\
\hline Ambulance & $46(70)$ & $32(48)$ \\
\hline Walk & $13(20)$ & $24(36)$ \\
\hline Hospital car & $2(3)$ & 4 (6) \\
\hline Police vehicle & $5(7)$ & $0 \quad(0)$ \\
\hline Taxi & $0 \quad(0)$ & $1(2)$ \\
\hline
\end{tabular}

1. Method of transfer unknown for 5 patients.

Seven (10\%) participants stated that their trust had a policy on transfer of psychiatric patients. Two did not know where the policies were kept and one participant provided a trust website address where such policy was available, but we could not access this information. Two acute trust respondents stated they were in the process of formulating a policy on transfer of psychiatric patients. None of the trusts forwarded copies of policies when we requested them.

\section{Discussion}

The results of our study of transfer policy of patients with mental illness from the emergency department show considerable heterogeneity. Departments vary in terms of how patients are transferred, who accompanies them, what risks are assessed and whose responsibility it is to assess these risks. Such variation probably reflects two things. First, the proximity of the acute mental health unit to the emergency department site will influence risk and the management of such risk. Second, psychiatric services vary in their development of liaison and crisis response teams. The presence or absence of such teams both in and out of normal working hours will considerably influence practice.

Of particular interest was the response to the scenario presented. Despite the clear clinical imperative of an acutely ill and threatening male patient, who has received sedative medication and is detained under the Mental Health Act 1983, there remains considerable variation in practice. With only $10 \%$ of trusts stating they have a transfer policy and none being able to provide us with one it suggests that the biomedical, risk and environmental management of this acute medical emergency is highly variable. A survey of rapid tranquillisation found few adverse events, but those that did occur were significant, including cardiovascular complications such as

\section{Table 2. Risks assessed prior to transfer}

Risk $n(\%)$

Not sure 25 (38)

Abscond, harm to self and others

$20(30)$

Abscond, harm to self and others, harm to vehicle

$12(18)$

environment

Harm to self and others, harm to vehicle

$1(2)$

environment

Harm to self and others only

7 (11)

Abscond only 
cardiac arrest (Pilowsky et al, 1992). Current best practice in rapid tranquillisation suggests that a patient's vital signs should be monitored every 5-10 min for $1 \mathrm{~h}$ and then every 30 min until the patient is ambulatory (Taylor et al, 2005). The Code of Practice of the Mental Health Act 1983 (Department of Health, 1999) requires that the approved social worker consider the most humane, least threatening and safest means of transferring the detained patient.

This study has a number of limitations that will affect the interpretation of the results. The sample, although large ( $n=82$ ), was not complete and we may not therefore be able to generalise the results. A telephone survey to the senior nurse or clinical services manager may not be the best means of ascertaining this information. As revealed in the response rates, contemporaneous pressure of work might have influenced the respondent's ability to give each question full consideration.

Despite these limitations, this survey has a number of important implications. Patients presenting to the emergency department with primary psychiatric problems are circumventing the customary avenues of primary and secondary psychiatric care. Many have significant mental disorder and are at risk of suicide, self-harm, violence and absconding into the community without appropriate treatment. Such patients require safe and comfortable transport if being admitted to a psychiatric unit, often some kilometres distant. Senior emergency department staff should have a clear understanding of the issues around the safe transfer of these patients. The significant discrepancies in practice revealed by our survey, coupled with likely local geographical and service variations, suggest that all emergency departments should have a policy governing the transfer of patients to acute psychiatric units. Liaison psychiatry departments would be ideally placed to facilitate and monitor the development of such policies.

There are a number of studies that would be helpful in this area. Further research should be aimed at monitoring the development of such policies and the factors that specifically influence variations in practice. The regular audit of practice against such policies is also an important piece of collaborative work for liaison psychiatry and emergency departments alike.

\section{Declaration of interest}

None.

\section{References}

DEPARTMENT OF HEALTH (1999) Mental Health Act 1983 Code of Practice. London: Department of Health

DEPARTMENT OF HEALTH (2004) Improving the Management of Patients with Mental III Health in Emergency Care Settings. London: Department of Health

PILOWSKY, L. S., RING, H., SHINE, P. J., et al (1992) Rapid tranquillisation. A survey of emergency prescribing in a general psychiatric hospital. British Journal of Psychiatry, 160, 831-835.

ROYAL COLLEGE OF PSYCHIATRISTS (2004) Psychiatric Services to Accident and Emergency Departments (Council Report CR118). London: Royal College of Psychiatrists.

TAYLOR, D., PATON, C. \& KERWIN, R. (2005) The Maudsley 2005-2006

Prescribing Guidelines (8th edn). London: Taylor \& Francis.

TINTINALLI, J. E., PEACOCK, F.W. \& WRIGHT, M. A. (1994) Emergency medical evaluation of psychiatric patients. Annals of Emergency Medicine, 23, 859-862.

YATES, K., PAXTON, R., GRIFFITHS, H. et al (2000) Changes in psychiatric admissions in rural northern England. Journal of Mental Health, 9, 105-111.
Charles Antwi Senior House Officer, Learning Disability Psychiatry, Exeter, *Adrian Flynn Specialist Registrar in Addictions, Cornwall Drug and Alcohol Service, Redruth, email: adeflynn@yahoo.com, Paul Chrichard Mental Health Liaison Nurse, Amanda Haddock Mental Health Liaison Nurse, Claire Johnson Mental Health Liaison Nurse, Jo Hammond Mental Health Liaison Nurse, Peter Aitken Consultant Liaison Psychiatrist, Director of Research and Development, Wonford House Hospital, Exeter

\section{Availability of patient records and psychiatric admission rate}

\section{AIMS AND METHOD}

Trainee psychiatrists often perform emergency mental health assessments. Traditionally, it has been considered that having access to past psychiatric records will reduce the likelihood of a patient being admitted. We examined whether the availability of records had an influence on admission by recording all contacts to the duty junior psychiatrist in two district general hospitals over a 6 -month period.

RESULTS

For those with chronic or enduring mental illnesses there is a $27 \%$ increase in the likelihood of admission if past records are available. For all other patients the increase is $10 \%$.

\section{CLINICAL IMPLICATIONS}

Contrary to our expectations, the availability of records increases the likelihood of admission to mental health admission units.
Maintaining patient records is an essential component of good clinical care (General Medical Council, 2001). The Scottish Executive considers avoiding admission and providing healthcare within community settings to be an important part of improving unscheduled care (Scottish
Executive, 2004). Mental health clinicians assume that the availability of clinical records reduces admission to acute psychiatry units. This is thought to be because decisions involving greater risk will be easier when clinicians are armed with more information. Second, previous records original papers 